\title{
O Sistema Nacional de Fomento: Formato Atual e Propostas de Reforma
}

\author{
The Brazilian Financial System: \\ Structure, Reforms and the Role of State
}

\author{
André Moreira Cunha* \\ Daniela Magalhães Prates* * \\ Carlos Eduardo Carvalho***
}

Resumo: O presente trabalho mostra a evolução e o desempenho dos bancos públicos e cooperativos, agregados em um conjunto heterogêneo denominado de sistema nacional de fomento (SNF). Argumenta-se que, a despeito das políticas implementadas no final dos anos 1990 e começo dos anos 2000, e que visavam à redução da presença do Estado na intermediação financeira, o SNF ainda tem um peso relevante no sistema financeiro brasileiro como um todo. Ademais, sugere-se que o SNF apresenta sinais de retomada de vitalidade após a crise financeira global de 2007-2008 e do subsequente ambiente da grande recessão. Por fim, são elencadas algumas reformas institucionais que poderiam fortalecer o SNF no que se refere à sua capacidade de contribuir para a consolidação de uma trajetória sustentável de desenvolvimento.

Palavras-chave: Bancos públicos. Sistema financeiro. Desenvolvimento. Brasil.

Abstract: In this paper, we present the evolution and performance of the Brazilian stateowned banks - commercial and development ones - and cooperatives. That institutions represent a heterogeneous system that we have named "national system of development financing institutions" (NSDFI). We argue that, despite the neoliberal reforms implemented during the 1990s and early 2000s, aimed at a reduction of the presence of the State in financial intermediation, Brazil still has an important share of its financial system under the umbrella of the NSDFI. Moreover, we suggest that this system has been recovering its vitality since the 2007-2008 global financial crisis and the subsequent great recession. We have also suggested some institutional reforms in the NSDFI in order to strength its capacity to support the economic development in contemporary Brazil.

Keywords: State-owned banks. Financial system. Development. Brazil.

JEL Classification: G2; O2.

\footnotetext{
* $\quad$ Doutor em Economia pela Universidade Estadual de Campinas (Unicamp). Professor associado do Departamento de Economia e Relações Internacionais da Universidade Federal do Rio Grande do Sul (UFRGS) e pesquisador do CNPq. E-mail: andre.cunha@ufrgs.br

* * Doutora em Economia pela Unicamp. Professora associada do Instituto de Economia da Unicamp e pesquisadora do CNPq. E-mail: danimagaprates@gmail.com

*** Doutor em Economia pela Unicamp. Professor do Departamento de Economia da Pontifícia Universidade Católica de São Paulo (PUC/SP) e do Programa de Pós-Graduação em Relações Internacionais San Tiago Dantas (Unesp-Unicamp-PUC/SP). E-mail: cecarv@uol.com.br
} 


\section{1 lntrodução}

A despeito dos processos de desregulamentação financeira nos anos 1980 e 1990 - que ocorreram pari passu ao avanço das ideias neoliberais e tiveram como um dos seus pilares a privatização de instituições públicas -, inúmeros países, desenvolvidos e em desenvolvimento, mantêm sistemas nacionais de fomento. $\mathrm{O}$ interesse pelo papel das instituições financeiras oficiais ganhou novo ímpeto com os desdobramentos da crise financeira global deflagrada em 2007-2008 e depois caracterizada pela "grande recessão". ${ }^{1}$ Países emergentes utilizaram seus bancos públicos para minimizar a contração do crédito privado, o que teve efeitos positivos sobre a retomada de dinamismo em suas economias, como reconhecido até pelo Banco Mundial (BM) (WORLD BANK, 2012).

É nesse contexto que o presente artigo analisa o perfil atual do que aqui se chama de Sistema Nacional de Fomento (SNF) da economia brasileira, com destaque para suas peculiaridades, e procura avançar na discussão normativa sobre os mecanismos de política creditícia e organização institucional que deveriam ser considerados para o fortalecimento do SNF. Nossa hipótese principal é que, mesmo tendo sofrido profundos ajustes no sentido de uma redução na participação estatal na intermediação financeira, da qual a privatização ou extinção da maioria dos bancos públicos estaduais é o exemplo maior, o Brasil logrou manter uma rede de instituições capazes de exercer as funções de estímulo ao desenvolvimento e tem condições de fortalecê-la por meio de políticas públicas voltadas para esse objetivo.

Para os propósitos deste artigo, o SNF refere-se ao conjunto de instituições públicas, bancárias (bancos de desenvolvimento e bancos com carteira comercial ou múltipla) e não bancárias (agências de fomento), e privadas (cooperativas, organizações de microfinanças) voltadas para o financiamento de setores e atividades prioritárias ou estratégicas para o desenvolvimento, bem como de segmentos da população e de regiões que não conseguem obter recursos no sistema financeiro privado. Essas instituições possuem fontes especiais de funding, com condições de prazo e custo diferenciadas (como exigibilidades sobre depósitos bancários e fundos de poupança fiscais e parafiscais), e esquemas institucionais de garantias.

O formato institucional desse sistema em termos do perfil das instituições e das fontes de funding varia bastante entre os países, com as influências do grau de desenvolvimento econômico, da evolução histórica do sistema financeiro doméstico, da configuração jurídica vigente (direito comum ou romano) e da tradição de política macroeconômica.

$\overline{1}$ Sobre as origens da assim chamada crise financeira global e seus desdobramentos, naquilo se convencionou chamar de "grande recessão". Ver, entre outros, os trabalhos organizados por Arestis, Sobreira e Oreiro (2011), Arestis e Sawyer (2012), Modenesi et al. (2012) e Cynamon, Fazzari e Setterfield (2013). 
A diversidade de arranjos institucionais persistiu após a onda de privatizações das instituições financeiras públicas. Os bancos públicos e seus congêneres continuam com uma participação ainda relevante no total dos ativos bancários, especialmente nas economias emergentes. Em 2002, em mais de 40 países emergentes, incluindo Brasil, Rússia, Índia e China, os ativos desses bancos somavam mais de $25 \%$ do total dos ativos dos bancos (HANSON, 2004). Mesmo em economias avançadas, como as da França, Alemanha e Japão, os sistemas financeiros mantiveram seu caráter misto, com a participação de instituições privadas e públicas (WORLD BANK, 2012). Portanto, o desenvolvimento econômico e o fortalecimento dos sistemas financeiros, inclusive com o aprofundamento dos mercados privados de dívidas de longo prazo, não foram acompanhados necessariamente pelo desaparecimento do SNF.

Os argumentos deste artigo estão organizados da seguinte forma: após esta breve introdução, a segunda seção apresenta a perspectiva analítica subjacente, que destaca a relação entre Estado e mercados financeiros, com ênfase para a tradição teórica keynesiana; a terceira seção resume a evolução histórica do SNF brasileiro e busca caracterizar seu perfil atual; e, por fim, a quarta seção traz as considerações finais, resumindo os argumento e as principais evidências e indicando proposições de políticas para o aperfeiçoamento do sistema.

\section{Estado e Intermediação Financeira: Aspectos Históricos e Teóricos}

O debate sobre o desenvolvimento econômico tem polarizado posições entre os que defendem e os que criticam a ideia de que os mecanismos de mercado são suficientes para garantir um crescimento sustentável e equilibrado. Entre as críticas, destaca-se a percepção de que o Estado tem um papel crucial na indução e, em certas circunstâncias, no comando do processo de desenvolvimento. Alguns críticos argumentam que a ação estatal é diretamente proporcional às fragilidades e insuficiências dos mercados e ao atraso relativo de cada país frente à fronteira tecno-produtiva. Isso explicaria a maior presença econômica do Estado nos países de desenvolvimento retardatário.

A visão pró-mercado tem sido sustentada pelo mainstream ${ }^{2}$ dos economistas profissionais e pelos organismos multilaterais de maior influência, como o FMI e o Banco Mundial. Enfatiza-se que o mercado é a instituição que garante a maior eficiência na alocação dos recursos escassos. Os preços livremente determinados nos mercados sinalizariam a escassez relativa dos fatores de produção e, assim, indicariam os padrões de especialização produtiva. A partir do pós-guerra, a experiência de industrialização das economias periféricas tem servido de pano de fundo para

2 Por simplificação, o presente artigo trata as expressões mainstream, ortodoxia e visão convencional como sendo equivalentes. 
a explicitação dessas posições. Em particular, o caso bem-sucedido de crescimento sustentado dos países asiáticos tornou-se o centro das principais controvérsias.

Na perspectiva crítica ao mainstream convergem distintas tradições teóricas, inspiradas nos trabalhos seminais de autores como Marx, Keynes, Schumpeter, no estruturalismo cepalino e nas demais abordagens heterodoxas associadas à emergência da economia do desenvolvimento (CIMOLI; DOSI; STIGLITZ, 2009; PEREZ; PRIMI, 2009). Em uma perspectiva de maior fôlego histórico, como sugerem, entre outros, Gerschenkron (1962), Reinert $(1999,2007)$ e Chang (2002), a noção de que o ativismo estatal está diretamente associado ao progresso econômico das nações remonta, pelo menos, ao período do mercantilismo. O argumento da proteção da indústria infante de Alexander Hamilton e Friedrich List tornou-se popular em nações emergentes que procuravam reproduzir a trajetória britânica de revolução industrial. Da mesma forma, a noção de que o desenvolvimento econômico implica na mudança qualitativa das estruturas produtivas, em que as inovações tecnológicas encontram um papel de centralidade, está fortemente assentada na obra de Schumpeter $(1961,1983)$ e encontra precedente na análise de Marx (2008).

No centro do antagonismo entre as visões convencional e heterodoxa, ganhou destaque o assim chamado Paradigma do Estado Desenvolvimentista (ou PED, de agora em diante), associado aos trabalhos seminais de Johnson (1982), Amsden (1989), Wade (1990), Chang (1994), Evans (1995), entre outros, com seus desdobramentos posteriores (RAVENHILL, 2008; WOO-CUMINGS, 1999). Em essência, o PED se refere ao conjunto de contribuições para a explicação do desenvolvimento asiático, particularmente do Japão e dos NICs (newly industrialized countries) de primeira geração (Taiwan, Coreia do Sul, Cingapura e Hong Kong), e que analisam o papel das políticas públicas voltadas à construção de novas estruturas produtivas e capacidades tecnológicas. As pesquisas associadas ao PED têm enfatizado o estudo das políticas industriais e direcionamento do crédito, gerando a conclusão de que o Estado teria sido um ator central na conformação do assim chamado "milagre asiático". Essa tradição se afasta das explicações convencionais que explicam o sucesso asiático por meio das estratégias de extroversão comercial, com a adoção de políticas comerciais supostamente neutras e manutenção de um ambiente de estabilidade macroeconômica (WORLD BANK, 1993).

Nesse sentido, o PED se insere naquele conjunto de paradigmas críticos à visão de que o desenvolvimento é o resultado último e exclusivo da atuação das forças de mercado em ambientes competitivos, em que o Estado tem por papel central manter a estabilidade de preços e o bom funcionamento das instituições que protegem os direitos de propriedade. À luz da experiência asiática e de outras economias maduras e periféricas bem-sucedidas na consolidação de trajetórias sustentadas de desenvolvimento, os autores associados ao PED dão destaque à 
importância de se estruturar um padrão de financiamento capaz de sustentar um elevado nível de alavancagem financeira, em que bancos - públicos ou privados garantiriam os recursos necessários para o financiamento dos investimentos.

A organização do sistema financeiro e a canalização do crédito para as atividades produtivas têm sido apontadas como sendo o sistema nervoso central das políticas desenvolvimentistas. Elementos como a existência de participação acionária cruzada entre grupos financeiros e não financeiros geraria um compromisso solidário entre as partes envolvidas na viabilização de projetos de longo prazo de maturação. Da mesma forma, as políticas públicas de incentivo à poupança privada gerariam recursos, a baixo custo, para os bancos (CHANG, 2006; JOMO, 2001). A coordenação do Estado e seu estrito controle sobre o crédito regulariam a liquidez do sistema e a eficiência na aplicação dos recursos. Em síntese, constituir-se-ia um "mercado de capitais interno" (ZYSMAN, 1983) capaz de equacionar, de forma eficiente, os problemas de assimetria de informações, subdesenvolvimento dos mercados de capitais, falta de coordenação nas decisões privadas de investimento, comportamentos rent-seeking, entre outros, típicos da experiência de industrialização tardia.

Para a abordagem convencional, a presença relevante de instituições financeiras públicas em vários países é justificada pela existência do que se chama de imperfeições ou falhas de mercado, como informação incompleta e concorrência imperfeita, que impedem que muitas atividades e setores tenham acesso a recursos captados no mercado. Assim, essas características dos mercados financeiros, que o seu aprofundamento não conseguiu eliminar, seriam uma justificativa, mesmo após as ondas de privatizações, para a presença ainda relevante de instituições públicas, até em países com sistemas financeiros mais profundos, como os Estados Unidos (CINTRA, 2006).

Como ressaltam Deos e Mendonça (2010), os conceitos de "falhas de mercado" e geração de externalidades servem de base para argumentos convencionais que resultam em quatro abordagens sobre o papel das instituições públicas, no caso de uma atuação não adequada do setor privado.

A chamada "visão social" baseia-se na ideia de que as empresas e os bancos públicos são criados para solucionar falhas de mercado sempre que os benefícios dessa intervenção superarem os custos. Na presença de imperfeições de mercado, o equilíbrio resultante não é eficiente e uma intervenção pode melhorar o bem-estar da sociedade. "A ênfase, pois, está na deficiência gerada pelos mercados que não financiam investimentos importantes do ponto de vista social" (DEOS; MENDONÇA, 2010, p. 58).

A segunda visão, "desenvolvimentista", na qual a "visão social" pode ser tida como uma variante, parte de que o baixo desenvolvimento de instituições financeiras nos países mais atrasados estimularia desconfianças por parte dos bancos 
privados no financiamento de atividades de longo prazo. Nesse contexto, o Estado deveria criar bancos para alavancar o crescimento econômico (NOVAES, 2007). Essa linha de argumentação sublinha a necessidade de intervenção em algumas situações específicas, que de algum modo derivam do mau funcionamento dos mercados existentes, ou mesmo de sua inexistência, podendo, assim, constituir um empecilho ao desenvolvimento (DEOS; MENDONÇA, 2010).

Já a "visão política" é bastante crítica em relação à existência de instituições financeiras públicas. Ela percebe os bancos públicos como sendo utilizados pelos detentores do poder, muito mais para prover emprego, subsídios e benefícios a seus aliados políticos do que na promoção do desenvolvimento do país como um todo. A "visão de agência" estaria num meio termo entre as duas visões social/desenvolvimentista e política. Essa visão considera a possibilidade de intervenção do Estado para melhorar a eficiência alocativa (assim como a visão social), mas também destaca as deficiências geradas pela intervenção pública. (NOVAES, 2007).

Neste artigo, as justificativas convencionais para a existência das instituições financeiras públicas, que dão a base fundamental para o SNF, são consideradas insuficientes para o entendimento do papel dessas instituições e do SNF, tanto nas economias capitalistas em geral, quanto nos países em desenvolvimento.

$\mathrm{Na}$ abordagem teórica schumpeteriana-keynesiana-minskyana aqui adotada, o SNF não deixa de ser necessário quando a economia atinge um patamar mais elevado de desenvolvimento, com sistemas financeiros maduros (HERMANN, 2011). Isso porque as instituições financeiras privadas, enquanto agentes capitalistas em busca de lucros, estão submetidas a uma lógica intrínseca de valorização da riqueza que desaconselha operações de maior risco e menor retorno. Na sequencia, apresenta-se sinteticamente esse perspectiva com base, principalmente, nas contribuições de Freitas (1997 e 2010). As demais referencias serão citadas ao longo do texto.

O papel fundamental da moeda de crédito criada pelo sistema bancário para a dinâmica de acumulação de capital nas economias capitalistas foi destacado tanto por Schumpeter (1983), quanto por Keynes (2012a, 2012b, 2012c). Para esses autores - e seus seguidores, entre os quais se destaca Minsky (1986) -, ao contrário da abordagem convencional, a existência de bancos ${ }^{3}$ emissores de moeda escritural libera os investidores de qualquer necessidade prévia, não apenas de poupança, mas também de riqueza acumulada no passado.

Os bancos administram ativamente os dois lados do balanço e utilizam, igualmente, outros expedientes, como as transações fora do balanço. Como a preferência pela liquidez dessas instituições depende de suas considerações otimistas ou pessimistas sobre o estado dos negócios ao longo do ciclo econômico, a evolução

3 Vale mencionar o conceito de banco aqui utilizado: intermediários financeiros que têm a capacidade de criar moeda de crédito, sob a forma de depósito à vista, o principal meio de pagamento e liquidação dos contratos nas economias capitalistas. 
do crédito tende a ser pró-cíclica, sobretudo se o sistema bancário for essencialmente constituído por instituições privadas com fins lucrativos. Assim, ao longo dos períodos de expectativas otimistas, pressionados pela concorrência, os bancos concedem crédito sem exigir garantias seguras. A expansão do endividamento se faz, então, com riscos subestimados. Isso porque, na busca incessante de valorização, um banco que adote um comportamento mais prudente vis-à-vis aos seus rivais arrisca-se a perder fatias do mercado. Em contraste, quando as expectativas se deterioram, os bancos tendem a contrair a concessão de crédito, reduzindo linhas e prazos, elevando os juros e as exigências de garantia.

Como a assunção excessiva de risco pelos bancos na fase de auge, o excesso de prudência na fase de reversão é característica intrínseca das atividades bancárias com fins lucrativos. Contudo, ao contrair o crédito, reduzindo ou não renovando as linhas, os bancos contribuem para a fragilidade financeira dos seus clientes, gerando um ciclo vicioso de aumento de inadimplência. Em certas circunstâncias, os bancos decidem racionar fortemente o crédito, refreando o crescimento econômico, ou mesmo conduzindo à regressão da produção e dos investimentos.

Para limitar a instabilidade inerente ao sistema bancário, as autoridades procuram impor regras de prudência para o funcionamento dos bancos, que se aplicam sobre a composição e qualidade do crédito e sobre os níveis de endividamento, entre outros. No entanto, com as inovações financeiras, os bancos tentam burlar todo e qualquer controle. Os novos instrumentos e procedimentos contribuem para ampliar a complexidade das estruturas financeiras e das relações entre os devedores e os credores. O resultado, como bem apontou Minsky (1986), é o aumento da instabilidade da economia.

Embora não adote de forma explícita o conceito de concorrência enquanto um processo de busca incessante pela valorização da riqueza, como ex-orientando de Schumpeter, Minsky (1986, p. 226) tem claro que a atividade bancária é um "[...] negócio lucrativo, inovativo e dinâmico [...]" e que o ativismo dos bancos "[...] afeta não só o volume e a distribuição das finanças, como o comportamento cíclico dos preços, rendas e emprego.". Em sua formulação, as inovações financeiras desempenham um duplo papel. De um lado, são utilizadas pelos bancos para ampliar suas possibilidades de ação e, por consequência, de obtenção de lucro - ou seja, a pesquisa e o desenvolvimento de inovações financeiras são impulsionados pelas mesmas motivações que no setor produtivo. De outro lado, essas inovações - que, na abordagem de Minsky, nascem tipicamente das necessidades de uma economia em forte crescimento - desempenham o papel de atenuar o aumento pró-cíclico das taxas de juros, tornando possível a ampliação do nível de endividamento da economia.

Assim, se de um lado as atividades de um "sistema financeiro complexo, intrincado e em constante evolução” conferem grande flexibilidade ao financiamen- 
to da acumulação de riqueza, indispensável ao dinamismo da economia capitalista, de outro lado o processo de financiamento da economia constitui fonte de instabilidade, na medida em que conduz à formação de ciclos econômicos.

É preciso ressaltar, contudo, que as inovações financeiras não respondem apenas às necessidades de uma economia em forte crescimento ou em uma conjuntura favorável. Impulsionados pela lógica concorrencial, os bancos e demais instituições financeiras desenvolvem novos instrumentos e procedimentos, igualmente em condições de estagnação econômica ou de deflação das dívidas.

Na lógica conflitante que opõe a busca de valorização da riqueza pelos bancos e a natureza de "bem público" da função monetária (POLANYI, 1988), que essas instituições privadas com fins lucrativos desempenham na economia capitalista, reside o traço distintivo da concorrência bancária. Em virtude desse conflito irreconciliável, o espaço e as formas da concorrência apresentam a particularidade de serem objetos das tentativas de circunscrevê-los aos limites fixados pela regulamentação, que variam de acordo com a estrutura institucional e jurídica existente em cada país. Para limitar a instabilidade inerente ao sistema bancário, as autoridades procuram impor regras de prudência para o funcionamento dos bancos, que se aplicam sobre a composição e qualidade do crédito e sobre os níveis de endividamento, entre outros. Porém, esses limites não são imutáveis. Ao contrário, evoluem com o desenvolvimento da economia, pois os bancos reagem às modificações no ambiente macroeconômico, regulatório e competitivo no qual atuam e, ao mesmo tempo, agem ativamente sobre as transformações nele produzidas.

Exatamente por estarem submetidas à lógica de valorização da riqueza, as instituições financeiras privadas não se envolvem espontaneamente com o financiamento de alguns setores e/ou atividades considerados prioritários e/ou estratégicos para o desenvolvimento econômico, em virtude do risco elevado e/ou da baixa lucratividade que lhes caracterizam. Dentre esses setores e/ou atividades se destacam: investimentos de longo prazo de maturação; financiamento de exportações; atividades rurais; crédito habitacional para baixa renda; financiamento às micro e pequenas empresas; investimentos em inovação tecnológica.

O financiamento desses setores e atividades exige fontes de recursos especiais, em geral mobilizadas pelo setor público e com esquemas institucionais de garantias. A existência de subsistemas especiais de crédito, com fontes de funding específicas, para o financiamento desses setores e atividades prioritárias é uma característica compartilhada pelos sistemas financeiros de países desenvolvidos e em desenvolvimento.

Assim, mesmo países desenvolvidos com sistemas financeiros maduros não prescindem de um SNF. Como destaca Hermann (2011), na realidade o desenvolvimento econômico e financeiro exige a definição de novas estratégias de operação por parte dos bancos públicos e das demais instituições que integram o SNF. 
Além da função de garantir o financiamento de atividades de alto risco e/ou baixo retorno, o SNF cumpre três funções adicionais, que também independem do estágio de desenvolvimento dos sistemas financeiros domésticos. A primeira delas é a de que, em países com grandes disparidades sociais e regionais, as instituições do SNF desempenham a função de promover a inclusão bancária da população de baixa renda e/ou de minorias, bem como a inclusão regional, ou seja, garantir o financiamento às empresas (dos diversos setores empresariais) e famílias residentes em regiões mais pobres (AMADO, 2010). No caso da inclusão regional, como destaca Amado (2010), a atuação do sistema financeiro privado acaba reforçando, ao invés de atenuar situações de desigualdade regional. Nesse contexto, é fundamental a interferência do Estado mediante a criação de instituições públicas de natureza regional, isso porque essas instituições, que não se guiam pela lógica privada de valorização da riqueza, podem exercer o poder discricionário de financiar atividades com maior enraizamento local, ampliando o efeito multiplicador gerado na região.

A segunda função adicional é a de que, devido ao caráter pró-cíclico do crédito concedido pelos bancos privados, as instituições públicas são as únicas capazes de atuar de forma contracíclica quando a economia entra em fase de desaceleração, sustentando a demanda de crédito das empresas em momentos de retração do crédito privado e desempenhando integralmente o papel de instrumento de política financeira governamental. Vale mencionar que a atuação contracíclica dos bancos públicos brasileiros frente ao efeito contágio da crise financeira e econômica global de 2008-2009 foi fundamental para evitar uma paralisia do mercado de crédito doméstico e seus impactos adversos sobre a atividade econômica.

Como no setor bancário, que é oligopolizado, o acirramento da concorrência não se traduz, necessariamente, em concorrência via preço (ou seja, na queda das taxas de juros do crédito e, assim, dos spreads), a terceira função adicional se dá quando os bancos públicos com carteira comercial podem ser instrumentos de regulação do poder de mercado dos bancos, afetando a dinâmica concorrencial mediante a influência na formação de preços (spreads e, assim, taxas de juros na ponta do crédito, além das tarifas) ou mesmo a criação de novos produtos (idem). No Brasil, essa função reguladora da concorrência também tem sido desempenhada pelos dois principais bancos públicos federais com carteira comercial (Caixa Econômica Federal - CEF e Banco do Brasil - BB) no período recente, sobretudo desde março de 2012.

Assim como o perfil de cada SNF, o tipo de instituição bancária ou não bancária mais adequada para o desempenho de cada uma dessas quatro funções também é variável. Por exemplo, como destacado no parágrafo anterior, os bancos públicos com carteira comercial são os únicos capazes de desempenhar a função reguladora, por concorrerem diretamente com os bancos privados criadores de 
moeda. Ademais, como destacam Carvalho e Tepassê (2010), a capilaridade da rede comercial desses bancos contribui igualmente para o desempenho de outras funções, como a atuação contracíclica e a inclusão bancária e regional. Já bancos nacionais de desenvolvimento, como o Banco Nacional de Desenvolvimento Econômico e Social (BNDES), destacam-se no financiamento de investimentos de maior prazo de maturação e maior risco.

As instituições financeiras subnacionais (como agências de fomento, bancos públicos e bancos de desenvolvimento que atuam em âmbito estadual ou regional) também cumprem, em geral, um papel relevante na inclusão regional, pois tendem a ser mais comprometidas com o desenvolvimento local, mas também podem contribuir para a política financeira contracíclica. A experiência brasileira também é elucidativa a esse respeito. De acordo com Araujo et al. (2011), essas instituições também contribuíram para a ação anticíclica implementada pelos bancos públicos em 2009. Como os bancos privados repassadores de recursos do BNDES arcam com o risco de crédito das operações de repasse, eles também contraem essas modalidades de crédito em situações de maior aversão ao risco. Dessa forma, os bancos públicos comerciais e as instituições financeiras subnacionais podem ocupar o espaço deixado pelos bancos privados, contribuindo para que os recursos do BNDES atinjam os tomadores finais. Ademais, mesmo em situações normais, essas instituições podem se revelar mais adequadas para a distribuição regional e estadual dos recursos dos fundos fiscais, parafiscais e constitucionais.

É importante, igualmente, detalhar o papel das atividades de microfinanças como parte do SNF. As microfinanças ganharam destaque nas últimas décadas pela percepção das implicações negativas da dificuldade de acesso a financiamento por parte de microempreendedores, indivíduos de renda baixa ou muito baixa. O valor muito reduzido e a ausência de garantias formais colocam essas operações fora do interesse dos bancos privados, deixando os demandantes limitados ao autofinanciamento ou à obtenção de crédito com fornecedores ou com agiotas. O desenvolvimento de organizações voltadas para essas operações partiu da valorização do chamado capital social, redes de vizinhança e relacionamento, com as modalidades de aval solidário e a figura do agente de crédito. Passou-se, também, a destacar outras modalidades de serviços financeiros para esse público, como microsseguros, cartões de pagamento e de crédito, além de contas de poupança e de depósito simplificadas.

As organizações de microfinanças surgiram quase sempre como organizações privadas, patrocinadas por ONGs ou por entidades assistenciais, mas em geral contam com algum tipo de apoio de instituições públicas. No modelo mais tradicional, o funding inicial era dado pela instituição patrocinadora e era alimentado pelo depósito de parte do crédito liberado na forma de poupança dos beneficiados. 
O desenvolvimento das atividades de microfinanças é muito desigual entre países e regiões. Na América do Sul, por exemplo, o Brasil apresenta a singularidade de ter a maior das organizações desse tipo, o CrediAmigo, vinculada a um banco público regional, o Banco do Nordeste (BNB). Na mesma região, os dois maiores bancos comerciais em operação na Bolívia, o Banco Andes e o Banco Sol, eram organizações de microfinanças que evoluíram para a forma de grandes bancos de varejo, processo semelhante ao ocorrido na Indonésia com o Rakyat.

Merecem destaque também as diversas modalidades de crédito cooperativo, muito amplas e tradicionais em diversos países e regiões, em geral voltadas para indivíduos que desenvolvem atividades comuns ou relacionadas. Em alguns países, as cooperativas dispõem de organização financeira ampla e diversificada, com bancos e apoio variado de organizações públicas.

Por fim, vale destacar a relevância das questões ligadas à governança das instituições do SFN e à transparência de suas atividades para que seus objetivos sejam atingidos de acordo com o mandato que lhes é conferido pela sociedade. Em sentido amplo, pode-se definir governance como " $[\ldots]$ the process and structure for overseeing the direction and management of a corporation so that it carries out its mandate and objectives effectively" (LUNA-MARTÍNEZ; VICENTE, 2012, p. 19).

No que se refere a instituições financeiras públicas e a instituições financeiras privadas com suporte público ou com direção coletiva (organizações de microfinanças e cooperativas), as questões de governança incluem desde as relações entre dirigentes e controlador e o grau de autonomia do corpo técnico e das instâncias diretivas que possa protegê-los de pressões conjunturais e oportunistas, até a articulação com a sociedade civil em geral e com as comunidades em que sua atividade está focada (região, grupos beneficiados), além de universidades, instituições de pesquisa e fomento, com institucionalização de instâncias de consulta e de troca de experiências.

No campo da transparência, incluem-se mecanismos de prestação de contas à sociedade e ao controlador, com identificação do custo dos recursos públicos e parafiscais alocados, inclusive custos de oportunidade, em relação aos benefícios gerados. Entram nesse campo também a explicitação e a observância de critérios na concessão de crédito em condições especiais, bem como dos resultados esperados.

\section{Caracterização do Sistema Nacional de Fomento e Contexto Atual}

Com base na análise da seção 2, e seguindo as tradições teóricas heterodoxas aqui destacadas, pode-se sugerir que as experiências históricas de sucesso na conformação de estruturas econômicas robustas, diversificadas e competitivas guardam, ao menos, um elemento em comum: a participação ativa do Estado 
na criação de condições favoráveis ao desenvolvimento. Essa participação tem-se revelado em múltiplas dimensões: a) na construção da infraestrutura física (transporte, comunicações, energia, etc.), institucional (estabelecimento de instituições e regras para o funcionamento dos mercados existentes e dos setores novos introduzidos nas economias), humana (educação e desenvolvimento científico e tecnológico) e financeira (regulação do sistema financeiro doméstico e criação de instituições financeiras públicas voltadas para o financiamento do desenvolvimento); b) na produção direta de bens e serviços por meio das empresas estatais; c) pela manutenção de um ambiente macroeconômico compatível com objetivos de expansão da renda com transformação das estruturas econômicas e sociais em bases relativamente estáveis; e d) na criação de incentivos (administrativos e de preços) capazes de direcionar o ritmo de acumulação de capital. Nesse sentido, as políticas industriais, financeiras e de promoção do comércio exterior ganham relevo nas distintas realidades nacionais.

Ademais, os Estados e suas políticas respondem aos desafios impostos, em cada conjuntura histórica, às suas oportunidades e constrangimentos. O período entre o segundo pós-guerra e o final dos anos 1970 marcou o auge e declínio do consenso desenvolvimentista, em que, em meio ao ambiente geopolítico da Guerra Fria, assumia-se como normal, e mesmo desejável, o ativismo estatal na promoção do desenvolvimento, desde que respeitada certa divisão de tarefas entre Estado e mercados que preservasse espaços amplos para a atuação do setor privado.

É nesse contexto que se multiplicaram instituições específicas, como bancos públicos e, em especial, bancos de desenvolvimento, além de empresas estatais e estruturas governamentais de apoio ao desenvolvimento industrial, à inovação tecnológica e à promoção de exportações. Na especificidade brasileira, esse período viu a consolidação dos alicerces do bem-sucedido processo de industrialização, que conduziu o país ao status de oitava maior economia do mundo e oitavo maior produtor de manufaturas no final dos anos 1970.

Nucleados pelos grandes bancos federais, como BB, CEF, Banco Nacional da Habitação (BNH), Banco da Amazônia (Basa), BNB e BNDE (posteriormente BNDES), formou-se um SNF, que se completava com os bancos estaduais com atuação comercial, as caixas econômicas e os bancos estaduais e regionais de desenvolvimento. Tal estrutura não passou incólume pelos anos que se seguiram à crise da dívida externa (1982) e ao novo ambiente internacional, em que a ascensão do neoliberalismo e o fim da Guerra Fria formaram um novo consenso, contrário ao ativismo estatal. No Brasil, o processo de estabilização monetária nos marcos do neoliberalismo conformou um novo espaço regulatório, no qual as recomendações de política apontavam para a necessidade de forte redução da participação estatal na intermediação financeira, particularmente dos entes subnacionais (CINTRA, 2006; JAYME JÚNIOR; CROCCO, 2010; PAULA, 2011). 
A liquidação de dois grandes bancos em 1995, o Econômico, em agosto, e o Nacional, em novembro, precipitou a adoção de medidas visando ao fortalecimento do sistema financeiro. O Banco Central do Brasil (BCB) temia a ocorrência de uma crise bancária sistêmica, e, portanto, foi organizado um amplo esforço de reestruturação. A Resolução no 2.197, de 31 de agosto de 1995, autorizou a constituição de uma entidade privada, sem fins lucrativos, para gerir recursos voltados à proteção dos poupadores. Procurava-se minimizar o risco de uma corrida bancária derivada de uma perda de confiança na solidez das instituições financeiras (BANCO CENTRAL DO BRASIL, 1999, 2002). Posteriormente, essa iniciativa materializou-se na constituição do Fundo Garantidor de Crédito (FGC). Em novembro de 1995, surgiram outras iniciativas cruciais: a) a ampliação dos poderes do $\mathrm{BCB}$ para responsabilizar civilmente os controladores das instituições financeiras e os auditores independentes, além de fortalecer a sua possibilidade de tomar ações preventivas para saneamento de instituições fragilizadas, como, por exemplo, condicionar seus aportes de liquidez a mudanças societárias - fusões, incorporações ou cisões; b) o estabelecimento de incentivos fiscais para estimular a incorporação de instituições frágeis pelas mais saudáveis; e c) a criação do Programa de Estímulo à Reestruturação e ao Fortalecimento do Sistema Financeiro Nacional (Proer), dando condições para acelerar o processo de fusões e incorporações de bancos, especialmente pela constituição de uma linha especial de assistência financeira. Tais medidas atuariam a favor do processo de consolidação bancária, ao estimularem as mutações patrimoniais, ao mesmo tempo que o setor público assumiria parte do custo do ajuste patrimonial das instituições problemáticas.

Um passo adicional no saneamento do sistema foi o equacionamento dos desequilíbrios patrimoniais dos bancos oficiais estaduais, o que se deu no bojo de um ajuste fiscal mais amplo, que envolveu a assunção, por parte do governo federal, de passivos financeiros dos estados. Para tanto, lançou-se mão do Programa de Incentivo à Redução do Setor Público Estadual na Atividade Bancária (Proes). ${ }^{4}$ governo federal aportaria recursos capazes de reequilibrar patrimonialmente os bancos estaduais pela emissão de títulos federais. Os estados controladores dos bancos poderiam optar pela sua posterior privatização, extinção, transformação em agências de fomento ou saneamento (mantendo o controle das instituições).

Se o Proer e o Proes foram importantes no saneamento do sistema financeiro, haveria, também, de se criar condições para que os bancos estrangeiros pudessem ampliar sua participação no mercado brasileiro. Desde os anos 1930, a legislação tornou-se restritiva a essa participação. Mais recentemente, a atual Constituição Federal do Brasil foi explícita nessa limitação. Porém, somente em 1995, com a Exposição de Motivos n ${ }^{\circ} 311$, do Ministério da Fazenda, é que o go-

4 Criado pela MP $n^{\circ} 1.514$, de 07 de agosto de 1996, e normatizado no BCB pela Resolução $\mathrm{n}^{\mathrm{O}} 2.365$, de 28 de fevereiro de 1997. 
verno federal usou o atributo constitucional de abrir o mercado bancário para a entrada de novos players. Assim, além da ação direta de estímulo à concentração e às centralizações de capitais nesse setor, através do Proer e do Proes, o BCB passou a apostar no incremento da entrada de grupos estrangeiros no mercado doméstico.

Nessa quadra histórica, o BCB mostrou-se proativo ao implementar medidas visando reduzir o potencial de risco sistêmico no sistema financeiro nacional. Já em 1994, o BCB havia ratificado o Acordo da Basileia (Resolução no 2.099, de 17 de agosto de 1994). Em seus quatro anexos, foram estabelecidos parâmetros de funcionamento para as instituições financeiras (autorização de funcionamento, transferência de controle societário e reorganização) e limites prudenciais: capital e patrimônio líquido mínimos, limite de diversificação de riscos e limites de imobilização e endividamento. Em 1997, foi criado o Sistema Central de Risco de Crédito. Elevaram-se, sucessivamente, os requisitos de capital ponderado pelo risco do padrão básico do Acordo da Basileia. Buscando alinhar-se às recomendações do Comitê de Supervisão Bancária da Basileia, o BCB determinou a introdução de rígidos controles internos nas instituições financeiras e alterou os critérios de classificação e provisionamento dos créditos concedidos. Buscou-se, ainda, minimizar os riscos associados às variações de preços-chave, como as taxas de juros e o câmbio, bem como de operações com derivativos. Ampliou-se a divulgação das informações econômico-financeiras das instituições, com a disseminação trimestral de estatísticas. Em 2002, entrou em operação o novo Sistema Brasileiro de Pagamentos (SBP) com vistas a otimizar a eficiência do registro e a liquidação das operações financeiras.

Por fim, caberia enfrentar os desequilíbrios dos bancos públicos federais. No âmbito do Programa de Fortalecimento das Instituições Financeiras Federais (Proef), foram adotadas medidas de saneamento, tais como: a) transferência do risco de crédito para o Tesouro Nacional - com respeito aos créditos problemáticos em carteira -, ou cessão de crédito para a Empresa Gestora de Ativos (Emgea), empresa não financeira vinculada ao Ministério da Fazenda, criada especificamente para gerir créditos; b) troca de ativos de pouca liquidez e baixa remuneração por ativos líquidos, remunerados à taxa de mercado; e c) aumento de capital, realizado na CEF, no BNB e no Basa. Para evitar novas situações de desequilíbrio patrimonial, a legislação que criou o Proef previu a necessidade de explicitação, na lei orçamentária, dos subsídios associados aos programas de desenvolvimento econômico e social operados pelos bancos federais. Além disso, o BCB recomendou a adoção de aprimoramentos na governança corporativa das instituições de modo a compatibilizar suas ações de fomento com o equilíbrio financeiro prospectivo (BANCO CENTRAL DO BRASIL, 2002). 
Assim, entre a segunda metade dos anos 1990 e o começo dos anos 2000, quase todos os bancos estaduais, comerciais, múltiplos e de desenvolvimento passaram por processos de reestruturação no âmbito do Proes. Reestruturados e privatizados, tais agentes, que haviam servido tanto de importante papel de alicerces do desenvolvimento, quanto de instrumentos para o financiamento dos governos locais (em movimentos nem sempre compatíveis com a manutenção de sua solvência), foram virtualmente eliminados do sistema financeiro (ver Tabela 3 do Anexo A). Os poucos bancos sobreviventes e as novas estruturas, as agências de fomento, passaram a conviver em um ambiente regulatório novo. Os grandes bancos federais foram preservados e amplia-se a presença das instituições privadas com controle nacional e estrangeiro. Às vésperas da crise financeira global, o SNF apresentava a menor participação relativa no sistema financeiro nacional do período analisado (ver Anexo B).

Nos termos definidos nesta seção, o SNF é composto pelos bancos comerciais federais, pelo BNDES, pelos bancos e agências estaduais de desenvolvimento e bancos vinculados às cooperativas. A Tabela 1 e os gráficos do Anexo B mapeiam o sistema, com base nos dados do BCB, para todas as instituições em que há dados consolidados, o que exclui instituições de microfinanças e, em certos anos, cooperativas individuais. ${ }^{5}$

$5 \quad$ Foi utilizada a base de dados 50 maiores bancos e o consolidado do Sistema Financeiro Nacional (BANCO CENTRAL DO BRASIL, 2012), que disponibiliza as informações contáveis dos balancetes trimestrais em valores correntes. O período de cobertura é de 1995 até 2012, tomando-se por referência a posição em dezembro de cada ano. Como, ao longo do período estudado, houve várias mutações patrimoniais (fusões, aquisições, privatizações de bancos públicos, criação de novas instituições, etc.), adotou-se como critério metodológico considerar o sistema nacional de fomento como sendo o somatório dos respectivos agregados das instituições financeiras controladas pelo setor público (governo federal e governos estaduais) e cooperativas e bancos cooperativos. Os dados das instituições de menor porte, como, por exemplo, as agências de fomento, só foram considerados nos períodos em que a base os explicitava. 
Tabela 1 - Sistema nacional de fomento (dez. 2012)

\begin{tabular}{|c|c|c|c|}
\hline & Controle & $\begin{array}{l}\text { Ativo total (Dez. } \\
\text { 2012) - RS mil }\end{array}$ & \begin{tabular}{|l} 
Oper. de Crédito (Dez. \\
2012) - RS mil.
\end{tabular} \\
\hline \multicolumn{4}{|c|}{$\begin{array}{l}\text { 1. Consolidado Bancário } 1 \text { (instituições que captam depósito: Bancos Múltiplos com carteira comercial; Bancos Comerciais; } \\
\text { Caixa Econômica Federal; Cooperativas de Crédito) }\end{array}$} \\
\hline Banco do Brasil & Público & 1.087 .268 .923 & 490.532 .302 \\
\hline Caixa Econômica Federal & Público & 702.939 .666 & 353.739 .502 \\
\hline Banrisul & Público & 46.834 .051 & 23.177 .797 \\
\hline Banco do Nordeste do Brasil S.A. & Público & 31.888 .888 & 11.323 .086 \\
\hline Banco Cooperativo Sicredi S.A. & Privado nacional & 19.350 .956 & 8.744 .658 \\
\hline Bancoop & Privado nacional & 14.854 .670 & 5.101 .231 \\
\hline Banestes & Público & 12.392 .430 & 3.395 .197 \\
\hline Banco da Amazônia S.A. & Público & 10.517 .798 & 2.292 .698 \\
\hline $\mathrm{BRB}$ & Público & 9.428 .487 & 6.382 .220 \\
\hline Banco do Estado do Pará S.A. & Público & 3.728 .257 & 2.158 .198 \\
\hline Banco do Estado de Sergipe S.A. & Público & 2.942 .073 & 1.567 .997 \\
\hline \multicolumn{4}{|c|}{ 2. Consolidado bancário IV (demais IFs: bancos de desenvolvimento) } \\
\hline Banco Nacional do Desenvolvimento & Público & 693.840 .197 & 251.475 .981 \\
\hline Banco Regional do Extremo Sul & Público & 9.363 .452 & 7.872 .861 \\
\hline Banco de Desenvolvimento de Minas Gerais S.A. & Público & 3.611 .582 & 2.872 .674 \\
\hline Banco de Desenvolvimento do Espirito Santo S.A. & Público & 1.259 .687 & 806.410 \\
\hline \multicolumn{4}{|c|}{ 3. Consolidado não bancário (demais IFs: agências de fomento) } \\
\hline Badesul Desenvolvimento AF/RS & Público & 2.835 .468 & 2.285 .335 \\
\hline AF Paraná & Público & 1.373 .282 & 687.433 \\
\hline Nossa Caixa Desenvolvimento & Público & 1.228 .163 & 611.155 \\
\hline Desenbahia - Agência de Fomento do Estado da Bahia S.A. & Público & 810.191 & 397.519 \\
\hline AF do Estado de Santa Catarina S.A. & Público & 763.328 & 632.436 \\
\hline Agência de Fomento do Estado do Rio de Janeiro S.A. & Público & 368.863 & 50.928 \\
\hline Afeam - Agência de Fomento do Estado do Amazonas S.A. & Público & 350.824 & 116.669 \\
\hline Agência de Fomento de Goiás & Público & 124.154 & 57.284 \\
\hline Agência de Fomento do Rio Grande do Norte S.A. & Público & 49.561 & 9.605 \\
\hline Agência de Fomento do Estado de Pernambuco S.A. & Público & 38.027 & 828 \\
\hline AFAL & Público & 25.442 & 864 \\
\hline Agência de Fomento do Estado de Mato Grosso S.A. & Público & 20.465 & 4.925 \\
\hline Agência de Fomento do Amapá S.A. & Público & 11.313 & 6.582 \\
\hline Agência de Fomento do Estado do Tocantins & Público & 9.609 & 7.255 \\
\hline Piaui Fomento & Público & 8.759 & 1.621 \\
\hline Agência de Fomento do Estado de Roraima & Público & 7.949 & - \\
\hline Total & & 2.658 .246 .515 & 1.176 .313 .251 \\
\hline$\% \mathrm{SFN}$ & & $44,6 \%$ & $49,9 \%$ \\
\hline Memória: Sistema Financeiro Nacional & & 5.966 .747 .604 & 2.355.807.043 \\
\hline
\end{tabular}

Fonte: Elaboração própria a partir dos dados do Banco Central do Brasil (2012). 
Com base nessas informações pode-se dimensionar a representatividade atual desse conjunto de instituições, bem como sua evolução entre 1995 e 2002. Assim, em dezembro de 2012, o SNF foi responsável por 49\% do estoque de operações de crédito e $45 \%$ dos ativos totais do sistema financeiro nacional. Adicionalmente, o SNF respondeu por 51\% dos depósitos, 31\% do capital, $46 \%$ da força de trabalho e $42 \%$ do número de agências em funcionamento, o que revela sua importância e vitalidade.

Do ponto de vista de sua evolução recente, entre 1995 e 2012, os Gráficos 4 até 8 (do Anexo B) reportam a participação do $\mathrm{SNF}^{6}$ nos seguintes agregados do sistema financeiro nacional: ativos, operações de crédito, capital, depósitos e estrutura (pessoal e agências). Além disso, cada gráfico tem dois painéis: A para o $\mathrm{SNF}$, e $B$ para o subgrupo dos bancos de desenvolvimento (regionais e estaduais) e agências de fomento. Tal segmento foi destacado por ter sido objeto das políticas de redução da participação do Estado no setor financeiro ao longo dos anos 1990 e começo dos anos 2000, conforme observado na seção 3.

Com base nos gráficos, é possível inferir que o movimento geral do período foi de perda de participação relativa do SNF no sistema financeiro brasileiro, especialmente do segmento diretamente controlado pelos governos estaduais. Por outro lado, a partir de meados da segunda metade dos anos 2000, e, com maior intensidade, depois de 2008, nota-se alguma reversão dessa tendência mais geral. Isso se dá pela retomada das instituições federais, conforme analisado, entre outros, nos trabalhos organizados por Jayme Júnior e Crocco (2010). Tal movimento está em consonância com a constatação do Banco Mundial (WORLD BANK, 2012) de que o período em que se inaugura a crise financeira originada em 2007 e 2008 no mercado hipotecário estadunidense recoloca a importância de uma presença mais ativa do Estado nos mercados financeiros.

Esse olhar mais favorável nasce, entre outras coisas, da constatação de que os capitais privados tendem a ser pró-cíclicos, característica reforçada pelos desdobramentos da crise. Ademais, países que preservaram instituições de crédito oficiais puderam, por meio destas, atenuar o racionamento de crédito oriundo do setor privado. Nunca é demais lembrar que as instituições que hoje compõem o que aqui se denominada de SNF, assim como suas congêneres internacionalmente nasceram para garantir o crédito necessário ao desenvolvimento, em contextos

6 Em função das mutações patrimoniais do período, especialmente aquelas relacionadas com o processo de desestatização dos bancos estaduais e criação de agências de fomento, adotou-se o seguinte procedimento: para cada ano de referência, o SNF era composto pelas instituições públicas federais (BB, CEF, BNB, Basa e BNDES), pelas instituições financeiras controladas pelos governos estaduais (bancos comerciais, múltiplos, bancos de desenvolvimento, caixas econômicas e agências de fomento) e cooperativas (Bansicredi, Bancoop, Cresol Baser e Cresol Central). O grau de detalhamento das informações da base de dados do BCB varia no período estudado, com a abertura das instituições nos respectivos consolidados bancários, crescendo com o passar do tempo. 
históricos em que o setor privado não podia ou desejava atuar com a intensidade necessária (GERSCHENKRON, 1962; JAYME JÚNIOR; CROCCO, 2010; REINERT, 1999, 2007).

A vocação ao crédito do SNF se expressa no Gráfico 1, em que os componentes do SNF são comparados com os maiores bancos no quesito proporção das operações de crédito nos ativos totais. Nota-se que tal indicador é de 39\% para o conjunto do SNF, $44 \%$ para o agregado do SNF e oscila entre 33\% e $40 \%$ entre os grandes bancos privados de varejo (Itaú, Bradesco, Santander, HSBC e Citibank). Entre as instituições do SNF, ganham destaque a CEF, os bancos de desenvolvimento e as agências de fomento, com indicadores bem acima da média do sistema financeiro nacional. ${ }^{7}$ Para se colocar em perspectiva, os bancos nacionais de desenvolvimento compilados em recente estudo do Banco Mundial apresentam, em média, esse indicador na ordem de 76\% (WORLD BANK, 2012).

$7 \quad$ No caso do BNDES, bem como de outras instituições que operam fortemente como primeiro e segundo pisos, a relação crédito/ativos não captura integralmente o direcionamento dos recursos para o crédito, isso porque os repasses para outras instituições aparecem como "relações interfinanceiras" no seu balanço. Assim, no caso do BNDES, o esforço em gerar operações de crédito corresponderia a $70 \%$ do seu ativo, e não aos $36 \%$ quando se verifica exclusivamente a relação crédito/ativos. 
Gráfico 1 - Operações de crédito (\% do ativo total) em dez. 2012

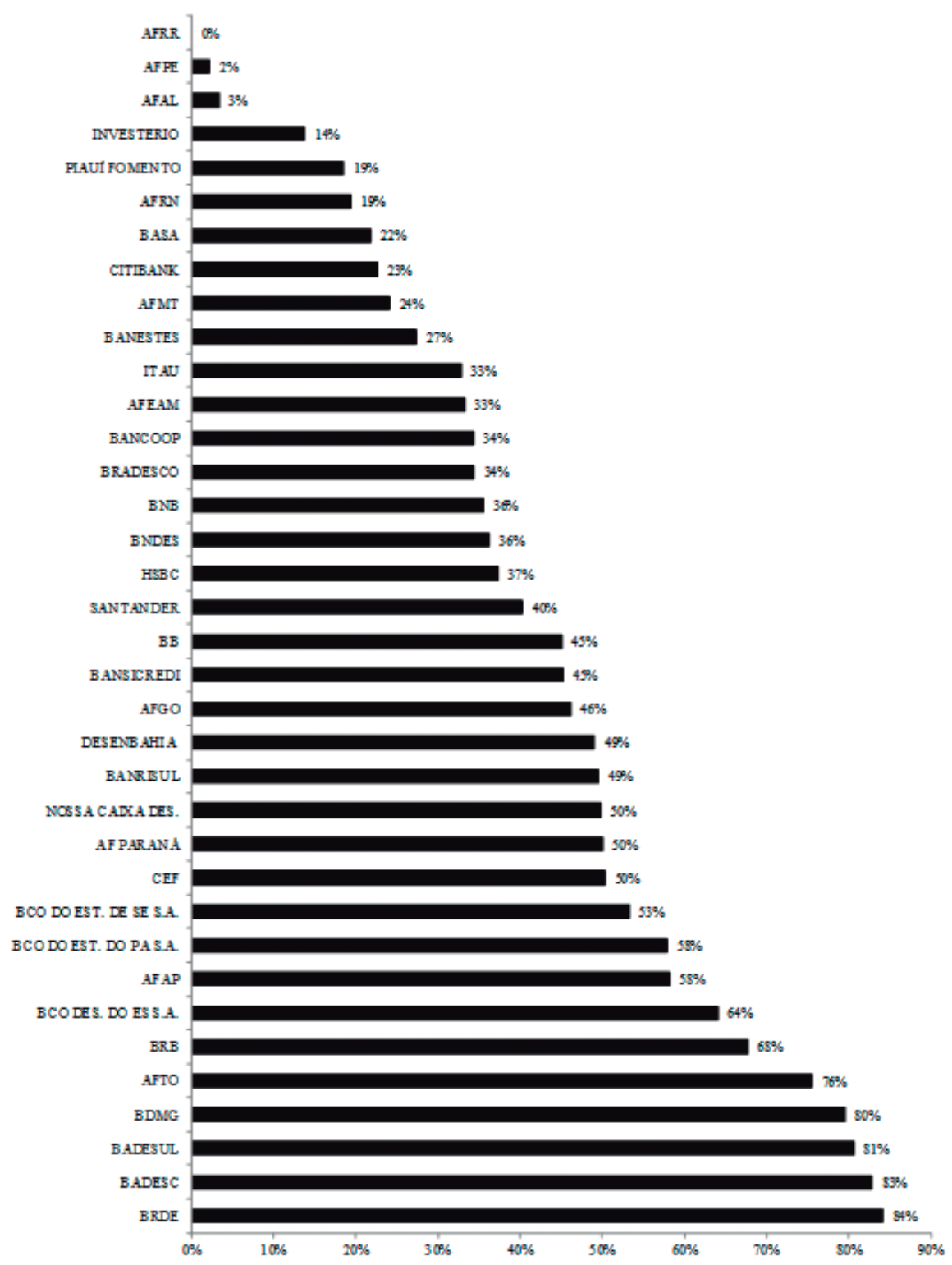

Fonte: Elaboração própria a partir dos dados do Banco Central do Brasil (2012).

O foco no crédito e a capacidade de ramificá-lo também podem ser observados na análise dos recursos do sistema BNDES, que é a principal fonte de funding para as operações crédito de longo prazo no Brasil. 
Assim, a Tabela 2 mostra: a) os desembolsos totais e diretos do BNDES; ${ }^{8}$ e b) a distribuição dos desembolsos dos agentes credenciados junto ao BNDES para repasse de suas linhas de financiamento.

Tabela 2 - Perfil das operações indiretas do BNDES (2012)

\begin{tabular}{l|r|r|r|r|c}
\hline & $\begin{array}{r}\text { Valor } \\
\text { (R\$ milhões) }\end{array}$ & $\begin{array}{r}\text { Part. } \\
(\%)\end{array}$ & $\begin{array}{r}\text { Operações } \\
\text { (unidades) }\end{array}$ & $\begin{array}{c}\text { Part. } \\
(\%)\end{array}$ & $\begin{array}{c}\text { Valor Médio } \\
\text { (R\$ mil) }\end{array}$ \\
\hline I. Sistema Nacional de Fomento & $\mathbf{3 4 . 1 5 5}$ & $\mathbf{4 1 \%}$ & $\mathbf{7 0 1 . 4 6 3}$ & $\mathbf{6 5 \%}$ & $\mathbf{4 9}$ \\
Instituições Federais* & 28.065 & $33 \%$ & 603.433 & $56 \%$ & 47 \\
BPEs, BDs, AFs, Cooperativas** & 6.090 & $7 \%$ & 98.030 & $9 \%$ & 62 \\
II. Instituições Privadas e Outras & $\mathbf{4 9 . 2 9 7}$ & $\mathbf{5 9 \%}$ & $\mathbf{3 8 0 . 4 5 8}$ & $\mathbf{3 5 \%}$ & $\mathbf{1 3 1}$ \\
Grandes Bancos Privados*** & 31.280 & $37 \%$ & 277.025 & $26 \%$ & 113 \\
Demais Instituições & 18.647 & $22 \%$ & 103.433 & $10 \%$ & 180 \\
Total das Operações Indiretas & $\mathbf{8 4 . 0 8 2}$ & $\mathbf{1 0 0 \%}$ & $\mathbf{1 . 0 8 1 . 9 2 1}$ & $\mathbf{1 0 0 \%}$ & $\mathbf{7 8}$ \\
\hline \multicolumn{7}{|c|}{ Memória } \\
\hline Operações Diretas & 71.910 \\
Desembolsos Totais & 155.992 \\
\hline
\end{tabular}

Fonte: Elaboração própria a partir dos dados do BNDES.

Nota: * Banco do Brasil, CEF, BNB, Basa e Finep; ** BRDE, Banrisul, BDMG, Cresol Baser, Cresol Central, Bansicredi, Bancoop, Bandes, Badesc, Desenvolve SP, Banestes, Desenbahia, BRB, Investe Rio, Banese, Afeam, Goiás Fomento, AF Paraná; *** Bradesco, Itaú Unibanco, Itaú BBA, Santander, Safra, Citibank e HSBC.

Em 2012, o total de desembolsos do BNDES foi de R\$156 bilhões, dos quais $\mathrm{R} \$ 72$ bilhões, ou 46\%, se deram de forma direta, e R $\$ 84$ bilhões, ou 54\%, de forma indireta. Ainda em 2012, as operações indiretas foram distribuídas em pouco mais de um milhão de operações. É possível observar que as instituições públicas federais, regionais e estaduais - e as cooperativas, que correspondem ao agregado aqui trabalhado como sendo o SNF, responderam por $41 \%$ dos valores desembolsados e por $65 \%$ do número de operações indiretas.

Em termos de valores, o ano de 2012 é representativo desse tipo de operações, em que predominam os agentes privados, que foram responsáveis por $59 \%$ dos desembolsos e 35\% das operações indiretas. Os grandes bancos privados, particularmente aqueles que possuem amplas redes de varejo, têm um peso importante em ambas as dimensões - valor e quantidade de operações. Todavia, o SNF se destaca em termos de capilaridade, o que também se expressa no menor valor médio dos desembolsos. Enquanto estes são, em média, de R\$ 47 mil nas instituições públicas federais, e $\mathrm{R} \$ 62$ mil entre as instituições públicas regionais e

$8 \quad$ Os desembolsos do BNDES podem ser separados em duas categorias: operações diretas, na qual o risco de crédito recai diretamente no BNDES, e operações indiretas, em que o risco é assumido pelas instituições credenciadas. 
estaduais e cooperativas, o setor privado opera com valores médios entre $\mathrm{R} \$ 113$ mil - grandes bancos privados -, figurando $\mathrm{R} \$ 180$ mil para as demais instituições. ${ }^{9}$

O Gráfico 2 revela a participação do SNF no total dos desembolsos indiretos entre 2000 e 2012. Nota-se a elevação, no período abordado, da importância relativa em termos do valor dos desembolsos das instituições públicas e cooperativas agregadas como SNF. Em termos de números de operações, verificou-se um recuou relativo na primeira metade dos anos 2000 e uma forte retomada a partir 2008.

É importante observar que o BNDES tem se esforçado em capilarizar o crédito, particularmente em sua atuação como banco de segundo piso. Novas linhas e programas de financiamento foram criadas e/ou aperfeiçoadas visando tal esforço, na medida em que as operações diretas do banco são usualmente para projetos de maior escala. Exemplos nesse sentido são os programas de crédito agrícola do governo federal ${ }^{10}$ e o cartão BNDES. ${ }^{11}$

9 Tais médias escondem uma grande dispersão no desempenho de cada instituição, cujas características específicas emergem quando de análises pormenorizadas, que não cabem no escopo deste trabalho. Assim, por exemplo, e tomando-se por referência o ano de 2012, e considerando-se os 19 maiores repassadores (responsáveis por 92\% do valor desembolsado e 95\% do número de operações) do BNDES, teríamos o seguinte ranking (do menor para o maior valor médio, em $\mathrm{R} \$$ mil): Banco do Brasil (42), Bansicredi (55), Bradesco (58), Banrisul (80), DLL/Rabobank (86), Grupo Volks (105), CEF (124), Grupo Fiat (143), Itaú Unibanco (166), Grupo Mercedez Benz (194), Volvo (205), BRDE (253), Grupo Safra (256), Caterpill (326), HSBC (451), Santander (586), ABC Brasil (685), Votorantim (802), Itaú BBA (1.015). O menor valor médio, em 2012, no universo das instituições credenciadas foi o do Uniprime, com R\$10 mil, e o maior valor foi o do BGT Pactual, com $\mathrm{R} \$ 39$ milhões. Para caracterizar tal dispersão, basta verificar que o desvio padrão excede em três vezes o valor médio dos desembolsos individuais. Por fim, a mediana dos desembolsos foi de R\$ 303 mil.

10 Tais como: Programa para redução da emissão de gases de efeito estufa na agricultura (ABC); Programa de modernização da agricultura e conservação de recursos naturais (Moderagro); Programa de modernização da frota de tratores agrícolas e implementos associados e colheitadeiras (Moderfrota); Programa de incentivo à irrigação e à armazenagem (Moderinfra); Programa de capitalização de cooperativas agropecuárias (Procap-Agro); Programa de capitalização de cooperativas de crédito (Procapcred); Programa de desenvolvimento cooperativo para agregação de valor à produção agropecuária (Prodecoop); Programa nacional de fortalecimento da agricultura familiar (Pronaf Investimento); Programa nacional de apoio ao médio produtor rural (Pronamp).

11 O cartão BNDES, que começou a operar em 2003, é um crédito pré-aprovado, com o valor limitado a R\$ 1 milhão, voltado para as micro, pequenas e médias empresas (MPMES). 
Gráfico 2 - O papel do Sistema Nacional de Fomento nos desembolsos das operações indiretas do sistema BNDES (2000-2012)

A - Valar

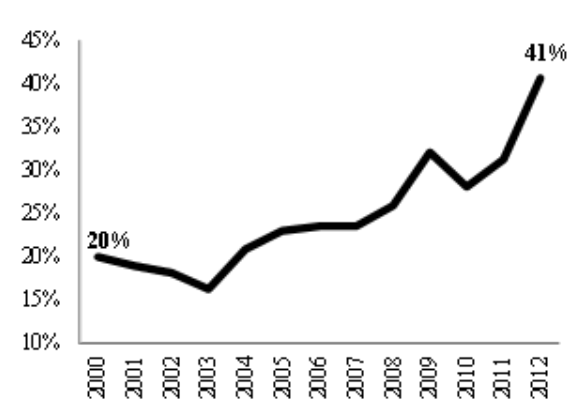

B - Númera de Operaçāes

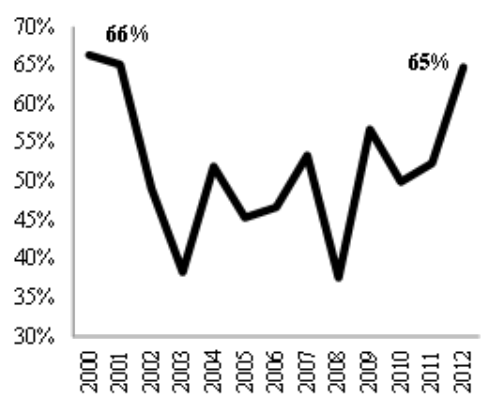

Fonte: Elaboração própria a partir dos dados do BNDES.

Em 2012, os programas agrícolas e o Finame Agrícola geraram desembolsos da ordem de $\mathrm{R} \$ 10,4$ bilhões em pouco mais de 100 mil operações. O cartão BNDES originou 708 mil operações em um montante de $R \$ 9,5$ bilhões, o que gera um valor médio por operação de $\mathrm{R} \$ 13,5$ mil, bem abaixo do valor médio geral anteriormente reportado. Se, em termos de valor, essa linha representou $11 \%$ dos desembolsos indiretos de 2012, em termos de número de operações tal participação foi de $65 \%$. Os agentes financeiros responsáveis por tal desempenho foram os seguintes: Banco do Brasil, Banrisul, Bradesco, Caixa Econômica Federal e Itaú, todos com amplas redes de varejo e tradição de operar com o mercado de micro, pequenas e médias empresas (MPMES).

Assim, ainda para o ano de 2012, os programas agrícolas e o cartão BNDES foram responsáveis por $23 \%$ do valor desembolsado e $74 \%$ das operações realizadas pelos agentes financeiros credenciados junto ao BNDES. No caso do cartão BNDES, 76\% dos desembolsos foram gerados pelo BB, CEF e Banrisul, instituições públicas que compõem o SNF. Coube ao Bradesco e ao Itaú os $24 \%$ restantes. Nos programas agrícolas, $47 \%$ dos desembolsos e $57 \%$ do número de operações foram gerados a partir das instituições que compõem o SNF. Conforme analisado na seção 2, a literatura reconhece que os segmentos de MPMES e o setor agropecuário tendem a gerar operações de maior risco, o que pode restringir a atuação das instituições privadas. As evidências aqui compiladas reforçam tal constatação, ou seja, tomando-se tais linhas e programas como proxy do esforço de financiamento do investimento nesses setores, predomina a atuação do SNF.

O Gráfico 3 mostra a evolução do valor médio dos desembolsos indiretos por três segmentos: o SNF, o setor privado e o total das operações indiretas. Para cada segmento, o valor médio foi apurado pela razão de dois somatórios: desembol- 
sos, em valores constantes, e número de operações. Para todo o período, o valor médio dos desembolsos do conjunto do SNF foi inferior ao observado no setor privado. Neste, a queda no valor médio está associada, principalmente, ao repasse de linhas como o cartão BNDES e programas agrícolas.

Gráfico 3 - Evolução das operações indiretas do BNDES - valores médios* - 20002012 (mil $R \$$, valores constantes de 2012)

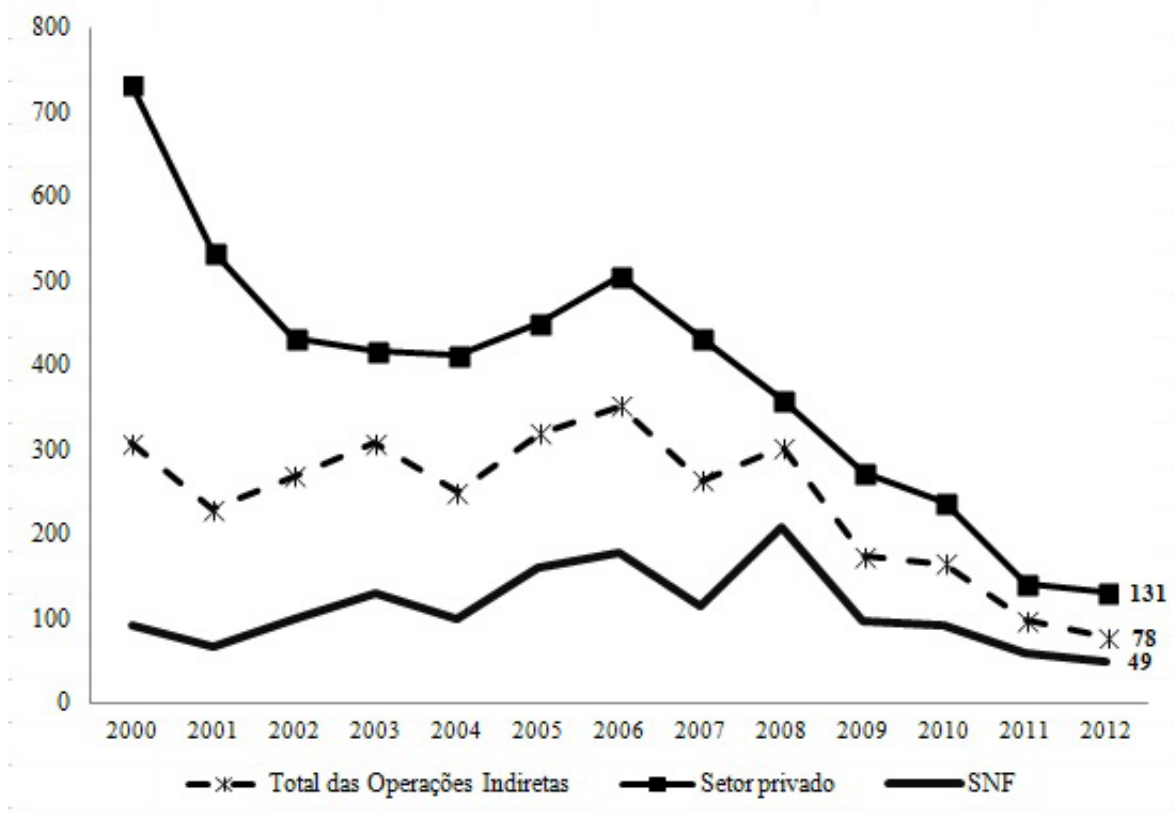

Fonte: Elaboração própria a partir dos dados do BNDES.

Nota: * Deflacionado pelo IGPM (índice mensal) médio.

Em síntese, a presente seção procurou dimensionar a importância relativa do SNF e sua evolução desde a segunda metade dos anos 1990, bem como caracterizar algumas dimensões do perfil de suas operações de crédito. Para tanto, foram utilizadas as bases de dados do BCB e do BNDES. Constatou-se que: a) a estratégia de redução da participação do Estado na intermediação financeira, implementada ao longo dos anos 1990, produziu os efeitos então desejados, tendo o SNF reduzido sua participação relativa no sistema financeiro nacional; b) por outro lado, tal redução tem sido revertida no período recente, particularmente depois de 2008; c) em termos da avaliação da atividade-fim da intermediação financeira, o SNF caracteriza-se pelo maior esforço em ofertar crédito, capturado no coeficiente operações de crédito como proporção do ativo total; e d) o crédito originado no SNF é mais pulverizado do que aquele oriundo do setor privado. 


\section{Considerações Finais}

O presente artigo procurou demonstrar que, a despeito das intenções mais gerais de profunda redução da participação estatal na intermediação financeira, expressas nas políticas de reestruturação do setor na segunda metade dos anos 1990 e começo dos anos 2000, o Brasil logrou superar a etapa neoliberal com uma rede ainda densa de instituições. Por decorrência, e diante dos efeitos adversos da crise financeira global e seus desdobramentos no quadro do que se tem denominado de a "grande recessão", sugeriu-se que tal rede pode ser mobilizada para os desafios colocados no presente e no futuro.

Ademais, o SNF respondeu de forma muito eficiente ao desafio de irrigar os canais de crédito, interrompidos pelo setor privado, quando do agravamento do cenário de crise no último trimestre de 2008. Isso fica evidenciado pela reversão na tendência prévia de redução na sua participação relativa no sistema financeiro como um todo, particularmente em termos dos saldos das operações de crédito. Para além desse fato, os desafios da retomada do desenvolvimento e a incapacidade do sistema financeiro privado de prover financiamento a todos os setores, atividades, regiões e segmentos da população, como destacado na seção 2, requerem um papel importante a ser desempenhado por essa rede de instituições públicas e cooperativas que forma o SNF.

Ao apresentar a evolução e as características recentes do SNF, verificou-se que a estratégia de redução da participação do Estado na intermediação financeira produziu os efeitos então desejados, tendo o SNF, particularmente no que se refere ao segmento das instituições controladas pelos governos estaduais, reduzido sua participação no sistema financeiro nacional. Ainda assim, verificou-se uma retomada consistente depois de 2008 , que pode ser atribuída ao crescimento das instituições controladas pelo governo federal. Outra característica que merece ser destacada é o maior esforço relativo das instituições que compõem o SNF em ofertar crédito e garantir que este seja capilarizado. Tipicamente, as operações de crédito do SNF têm um menor valor médio, o que representa o direcionamento dos recursos para os pequenos empreendimentos rurais e urbanos, sujeitos a maior risco de crédito. Vale dizer, reafirma-se que a função de fomento é a grande vocação do SNF, sendo seu papel como ofertante de crédito crucial para viabilizar a inclusão financeira social e regional, a ampliação das microfinanças, bem como a estruturação das grandes operações de investimento por meio dos repasses do BNDES, além de garantir o acesso de recursos de menor valor aos demais empreendimentos.

Posto isso, conclui-se que o SNF não somente constitui uma peça central da retomada do desenvolvimento da economia brasileira, como precisa ser fortalecido para continuar atuando em segmentos mais expostos ao viés negativo de sele- 
ção típico da gestão privada. Para além dos setores em que já atua de forma ativa, o aprimoramento do SFN deve partir de uma visão de sistema que contemple compreender a heterogeneidade e as especificidades de suas partes.

Futuros trabalhos deverão aprofundar esse tipo de diagnóstico, procurando retirar dele as implicações normativas pertinentes. Para contribuir nesse sentido, cabe ressaltar desde logo a importância de preservar e fortalecer o sistema de direcionamento de crédito, com esquemas institucionais de garantias, que poderiam ser operados pelos principais bancos públicos. Com isso, busca-se o atendimento de três das quatro funções destacadas na seção 2, quais sejam: fomento, ação contracíclica e inclusão bancária. Para tanto, é preciso fortalecer a rede de agências de fomento e bancos de desenvolvimento estaduais e regionais - para que possam operar com maior intensidade enquanto agentes capazes de garantir a capilaridade dos repasses do BNDES e de outras fontes de funding oficiais - e o acesso ao crédito aos pequenos empreendimentos rurais e urbanos, sujeitos a maior risco de crédito e que contratam operações de menor valor.

Deve-se identificar os mecanismos institucionais necessários para que se fortaleça tal rede de instituições, a partir de políticas coordenadas entre os governos central e subnacionais, tendo-se em conta as diferentes estruturas produtivas e capacidades institucionais locais. Assume-se que o governo federal deverá atuar ativamente na indução dessa nova etapa, para além do esforço que já vem sendo realizado para fortalecer as instituições sob seu controle direto. Assim como houve uma estratégia de reordenamento da atuação dos bancos públicos na era das reformas neoliberais, consubstanciada, por exemplo, no Proes, há que se estruturar sua antítese para o período atual. Da mesma forma deve-se proceder em relação ao Proes: o governo central poderia vincular a eventual renegociação das condições de pagamento da dívida dos estados ao fortalecimento das agências de fomento e bancos de desenvolvimento, especialmente no que se refere aos mecanismos de garantia de capitalização, funding e fortalecimento da governança corporativa. Mais especificamente, poderia ser facultado aos governos estaduais o direcionamento de parte da economia gerada com o pagamento dos serviços da dívida para a capitalização das AFs e BDs, em conjunto com a construção de modelos de governança que garantam a capacidade dessas instituições em cumprir sua missão institucional, o que gera maior exposição relativa ao risco e, simultaneamente, evita a constituição de passivos contingentes que onerem, no futuro, as contas públicas.

Para que a função reguladora dos bancos públicos comerciais continue sendo praticada, é necessário evitar tanto a ampliação da participação de acionistas privados no capital do BB, quanto a abertura do capital da CEF. Ademais, por desempenharem as quatro funções antes destacadas (fomento, ação contracíclica, regulação da concorrência e inclusão bancária), a avaliação do desempenho das 
instituições dos SNF deve considerar outros critérios, além da análise financeira dos balanços. Como propõe Freitas (2010), a avaliação dos bancos públicos (e, na perspectiva aqui adotada, das demais instituições do SNF) deve contemplar: o volume de empréstimos concedidos na fase de desaceleração econômica; a contribuição para a redução de spreads e tarifas nos diferentes segmentos do mercado de crédito; a presença e atuação em regiões menos favorecidas; o número de clientes ativos de baixa renda; o percentual de crédito destinado às micro e pequenas empresas; e a qualidade do atendimento. No caso das microfinanças e das cooperativas, o marco regulatório apresenta peculiaridades nos diversos países, da mesma forma que o perfil das instituições, o que dificulta muitas vezes a mensuração de sua atividade e da relevância que assumem.

\section{Referências}

AMADO, A. Bancos privados e públicos regionais em uma perspectiva de desenvolvimento regional. In: JAYME JR., F.; CROCCO, M. (Org.). Bancos públicos e desenvolvimento. Rio de Janeiro: Ipea, 2010. p. 49-72.

AMSDEN, A. H. Asia's next giant: South Korea and late industrialization. New York: Oxford University Press, 1989.

ARAUJO, V. L. et al. O sistema brasileiro de instituições financeiras subnacionais para o desenvolvimento: um panorama. Brasília: Ipea, 2011. (Texto para discussão, n. 1626).

ARESTIS, P.; SAWYER, M. (Ed.). The Euro crisis. New York: Palgrave Macmillan, 2012.

ARESTIS, P.; SOBREIRA, R.; OREIRO, J. L. (Ed.). An assessment of the global impact of the financial crisis. New York: Palgrave Macmillan, 2011.

BANCO CENTRAL DO BRASIL. 50 maiores bancos e o consolidado do sistema financeiro nacional. 2012. Disponível em: <http:/www4.bcb.gov.br/top50/port/top50.asp > . Acesso em: 27 jun. 2015.

. O Sistema financeiro nacional e o plano real. Brasília, DF: BACEN/DEDIP, 1999.

. Relatório de atividades, 1995-2002. Brasília, DF: BACEN/Diretoria de Fiscalização, 2002. CARVALHO, C. E.; TEPASSÊ, A. C. Banco público como banco comercial e múltiplo: elementos para a análise do caso brasileiro. In: JAYME JR, F.; CROCCO, M. (Org.). Bancos públicos e desenvolvimento. Rio de Janeiro: Ipea, 2010. p. 25 - 47

CHANG, H-J. Kicking away the ladder: development strategy in historical perspective. London: Anthem Press, 2002. (Paperback).

. The East Asian development experience: the miracle, the crisis and the future. London: Zed Books, 2006.

. The political economy of industrial policy. Londres: Macmillan, 1994. 
CIMOLI, M.; DOSI, G.; STIGLITZ, J. (Ed.). Industrial policy and development: the political economy of capabilities accumulation. Oxford; New York: Oxford University Press, 2009.

CINTRA, M. A. M. A reestruturação patrimonial do sistema bancário brasileiro e os ciclos de crédito entre 1995 e 2005. In: CARNEIRO, R. (Org.). A supremacia dos mercados e a política econômica do governo Lula. São Paulo: Unesp, 2006.

CYNAMON B. Z.; FAZZARI, S.; SETTERFIELD, M. (Ed.). After the great recession: the struggle for economic recovery and growth. Cambridge; New York: Cambridge University Press, 2013.

DEOS, S.; MENDONÇA, A. R. R. Uma proposta de delimitação conceitual de bancos públicos. In: JAYME JR., F.; CROCCO, M. Bancos públicos e desenvolvimento. Rio de Janeiro: Ipea, 2010. p. 49-72.

EVANS, P. Embedded autonomy: states and industrial transformation. New Jersey: Princeton University Press, 1995.

FREITAS, M. C. P. A natureza particular da concorrência bancária e seus efeitos sobre a estabilidade financeira. Revista Economia e Sociedade, Campinas, n. 9, p. 51-84, jun. 1997.

. Dinâmica concorrencial e bancos públicos: questões conceituais. In: JAYME JR., F. G; CROCCO, M. Bancos públicos e desenvolvimento. Rio de Janeiro: Ipea, 2010. p. 329-359.

GERSCHENKRON, A. Economic backwardness in historical perspective. Cambridge: Harvard University Press, 1962.

HANSON, J. A. The Transformation of State-Owned Banks. In: CAPRIO, G.; FIECHTER, J. L.; LITAN, R. E.; POMERLEANO, M. The Future of State-Owned Financial Institutions. Washington, DC: Brookings Institution Press, 2004 (p. 13-50)

HERMANN, J. ; Bancos Públicos em Sistemas Financeiros Maduros: perspectivas teóricas e desafios para os países em desenvolvimento. Revista de Economia Política, v. 31, n.3, julhodezembro, p. 397-414, 2011.

JAYME JÚNIOR., F.; CROCCO, M. Bancos públicos e desenvolvimento. Rio de Janeiro: Ipea, 2010.

JOHNSON, C. MITI and the Japanese miracle. Stanford: Stanford University Press, 1982.

JOMO, K. S. Growth after the Asian crisis: what remains of the East Asian model? G-24 Discussion, Mar. 2001. (Paper series, n.10).

KEYNES, J. M. A treatise on money I. In: JOHNSON, E.; MOGGRIDGE, D. (Ed.). The collected writings of John Maynard Keynes. v. 5. Cambridge; New York: Cambridge University Press, 2012a. Publicado originalmente em 1930.

A treatise on money I. In: JOHNSON, E.; MOGGRIDGE, D. (Ed.). The Collected Writings of John Maynard Keynes. v. 6. Cambridge; New York: Cambridge University Press, 2012b. Publicado originalmente em 1930.

The general theory of employment, interest, and money. In: JOHNSON, E.; MOGGRIDGE, D. The collected writings of John Maynard Keynes. Cambridge; New York: Cambridge University Press, 2012c. v. 7. Publicado originalmente em 1936. 
LUNA-MARTÍNEZ, J.; VICENTE, C. L. Global survey of development banks. Washington, D.C.: World Bank, 2012. (Policy research working paper, n. 5.969).

MARX, K. O Capital: crítica da economia política. Rio de Janeiro: Civilização Brasileira, 2008. 4 v.

MINSKY, H. P. Financial innovation and financial stability: observations and theory. In: FEDERAL RESERVE BANK OF ST LOUIS. Financial innovation: their impact on monetary policy and financial markets. Boston: Kluwer Mighoff, 1984. p. 21-41.

. Stabilizing an unstable economy. New Haven: Yale University Press, 1986.

MODENESI A. M. et al. (Org.). Sistema financeiro e política econômica em uma era de instabilidade. Rio de Janeiro: Campus/Elsevier, 2012.

NOVAES, A. Intermediação financeira, bancos estatais e o mercado de capitais: a experiência internacional. In: PINHEIRO, A. C.; OLIVEIRA FILHO, L. C. (Org.). Mercado de capitais e bancos públicos: análise e experiências comparadas. São Paulo: Contra Capa Livraria/ANBID, 2007. p. 35-132.

PAULA, L. F. Financial liberalization and economic performance: Brazil at the crossroads. New York: Routledge, 2011.

. Financial liberalization and economic performance: Brazil at the crossroads. London: Routledge, 2011.

PERES, W.; PRIMI, A. Theory and practice of industrial policy. Evidence from the Latin American experience. Santiago de Chile: Cepal, n. 137, Feb. 2009. (Serie Desarrollo Productivo).

POLANYI, K. A grande transformação: as origens da nossa época. Tradução de Fanny Wrobel. Rio de Janeiro: Campus, 1988. Publicado originalmente em 1944.

PRATES, D. M; FREITAS, M. C. Crédito bancário corporativo no Brasil: evolução recente e perspectivas. Revista de Economia Política, São Paulo, v. 33, n. 2, abr./jun. 2013.

RAVENHIL, J. Global political economy. 2. ed. Oxford; New York: Oxford University Press, 2008. REINERT, E. How rich countries got rich and why poor countries stay poor. New York: Public Affairs, 2007. 268-326, 1999.

. The role of state in economic growth. Journal of Economic Studies, v. 26, n. 4/5, p.

SCHUMPETER, J. A. Capitalismo, socialismo e democracia. Tradução de Ruy Jungmann. Rio de Janeiro: Fundo de Cultura, 1961. Tradução do original inglês: Capitalism, socialism, and democracy. Economistas).

. Teoria do desenvolvimento econômico. São Paulo: Abril Cultural, 1983. (Coleção Os

WADE, R. Governing the market: economic theory and the role of government in East Asian industrialization. Princeton: Princeton University Press, 1990. 
WOO-CUMINGS, M. (Ed.). The developmental state. Ithaca: Cornell University Press, 1999.

WORLD BANK. The East Asian miracle: economic growth and public policy. New York: Oxford University Press, 1993.

Bank, 2012.

ZYSMAN, J. Government, markets and growth: financial systems and politics of industrial change. Ithaca: Cornell University Press, 1983. 


\section{Anexo A - Sistema Bancário Brasileiro}

Tabela 3 - Indicadores selecionados do sistema bancário brasileiro: 1993 e 2001(\%)

\begin{tabular}{l|cc|cc|cc|cc}
\hline \multirow{2}{*}{\multicolumn{1}{c|}{ Discriminação }} & \multicolumn{2}{c|}{ Patrimônio } & \multicolumn{2}{c|}{ Ativos } & \multicolumn{2}{c|}{ Depósitos } & \multicolumn{2}{c}{$\begin{array}{c}\text { Operações de } \\
\text { Crédito }\end{array}$} \\
\cline { 2 - 10 } & $\mathbf{1 9 9 3}$ & $\mathbf{2 0 0 1}$ & $\mathbf{1 9 9 3}$ & $\mathbf{2 0 0 1}$ & $\mathbf{1 9 9 3}$ & $\mathbf{2 0 0 1}$ & $\mathbf{1 9 9 3}$ & $\mathbf{2 0 0 1}$ \\
\hline Bancos com controle estrangeiro & 7,3 & 30,7 & 8,4 & 29,9 & 4,8 & 20,1 & 6,6 & 31,5 \\
Bancos privados nacionais & 48,2 & 51,1 & 40,7 & 37,2 & 38,8 & 35,3 & 31,5 & 42,1 \\
Bancos Públicos & 44,0 & 16,1 & 50,9 & 32,0 & 56,3 & 43,2 & 61,8 & 24,8 \\
$\quad$ Bancos Públicos (inclusive Caixa Estadual) & 15,0 & 3,5 & 13,4 & 4,3 & 17,3 & 7,2 & 19,9 & 3,1 \\
Caixa Econômica Federal & 4,0 & 3,9 & 14,5 & 11,0 & 27,9 & 19,1 & 22,8 & 7,1 \\
$\quad$ Banco do Brasil & 24,9 & 8,8 & 22,9 & 16,8 & 11,1 & 17,0 & 19,1 & 14,5 \\
Cooperativas de crédito & 0,5 & 2,0 & 0,1 & 0,9 & 0,1 & 1,3 & 0,2 & 1,6 \\
Área Bancária & 100,0 & 100,0 & 100,0 & 100,0 & 100,0 & 100,0 & 100,0 & 100,0 \\
\hline
\end{tabular}

Fonte: Banco Central do Brasil.

\section{Anexo B - Evolução do Sistema Nacional de Fomento, 1995-2012 (posições} em dezembro de cada anol

Gráfico 4 - Ativos (\% do total do sistema financeiro)

\section{A. Sstema Nacional de Fomento}

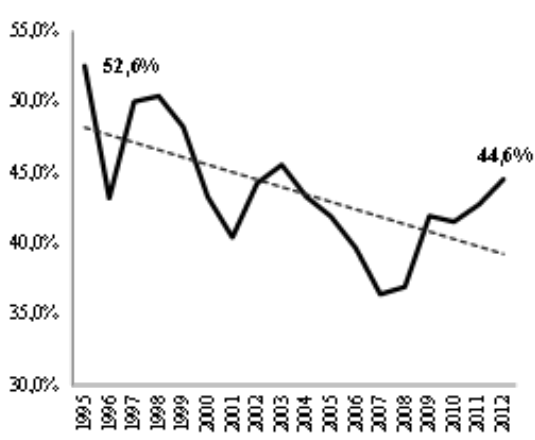

B. BDs Regionais/Estaduais e AFs

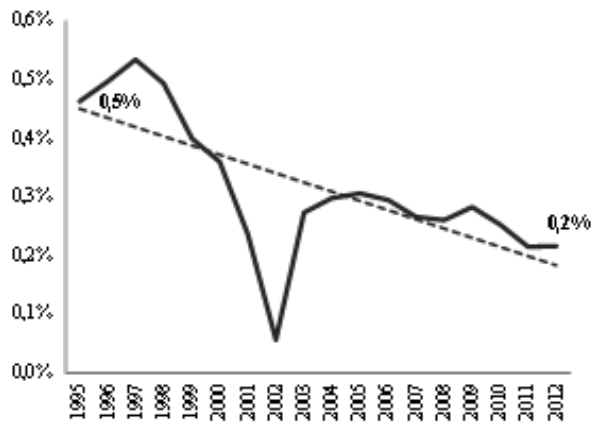

Fonte: Elaboração própria com base nos dados do Banco Central do Brasil. 
Gráfico 5 - Operações de crédito (\% do total do sistema financeiro)

A. Sistema Nacional de Fomento

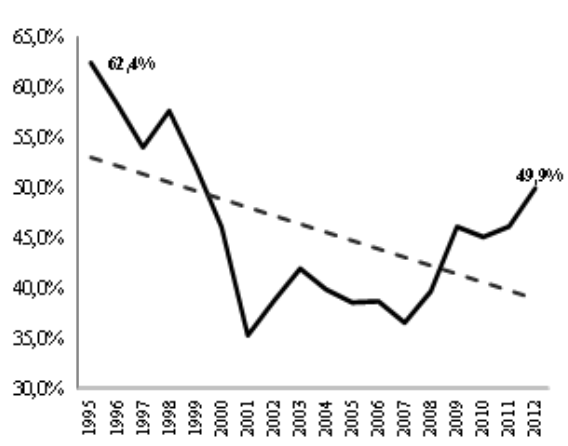

B. BDs Regionais/Estaduais e AFs

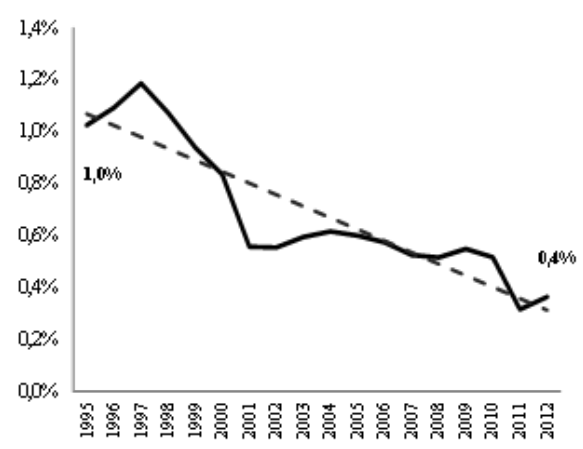

Fonte: Elaboração própria com base nos dados do Banco Central do Brasil.

Gráfico 6 - Patrimônio (\% do total do sistema financeiro)

\section{A. Sistema Nacional de Fomento}

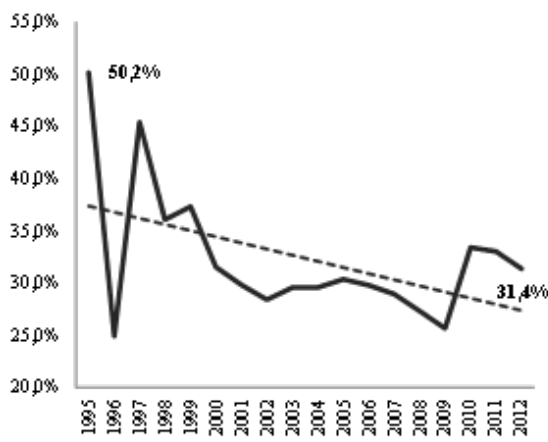

B. BDs Regionais'Estaduais e AFs

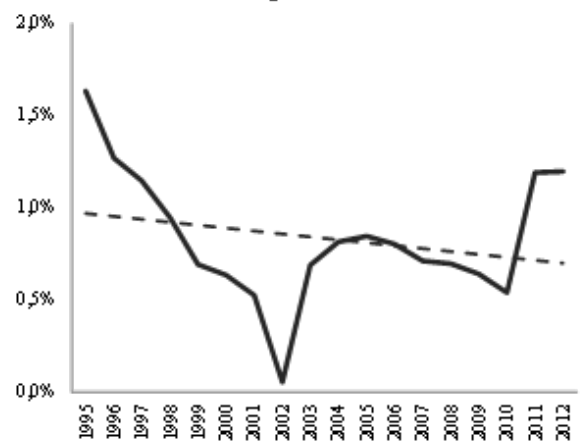

Fonte: Elaboração própria com base nos dados do Banco Central do Brasil. 
Gráfico 7 - Depósitos (\% do total do sistema financeiro)

\section{A. Sistema Nacional de Fomento}

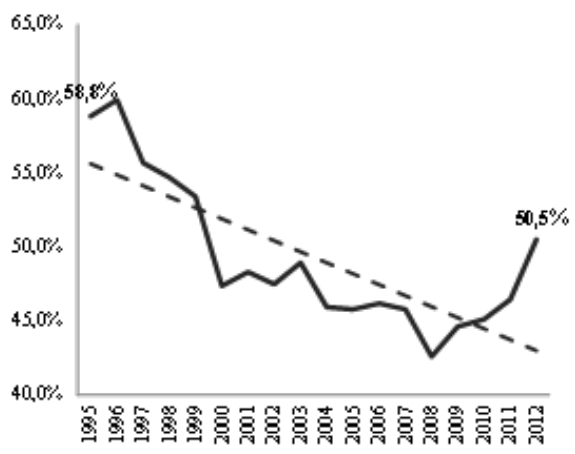

B. BDs Regionais/Estaduais e AFs

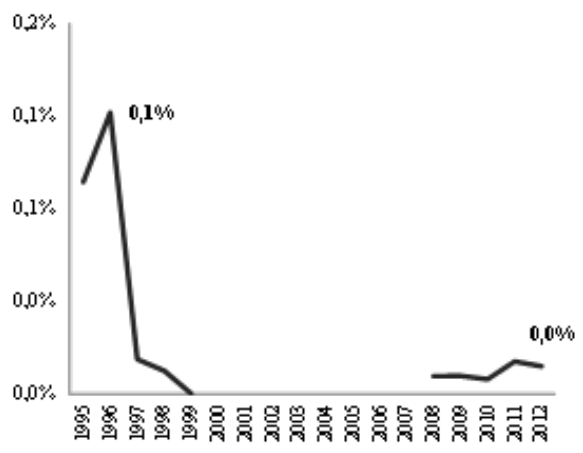

Fonte: Elaboração própria com base nos dados do Banco Central do Brasil.

Gráfico 8 - Agências e número de funcionários (\% do total do sistema financeiro)

A. Sistema Nacional de Fomento

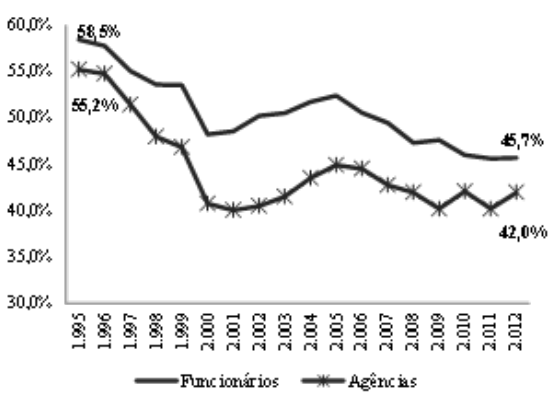

B. BDs Regionais/E staduais e AFs

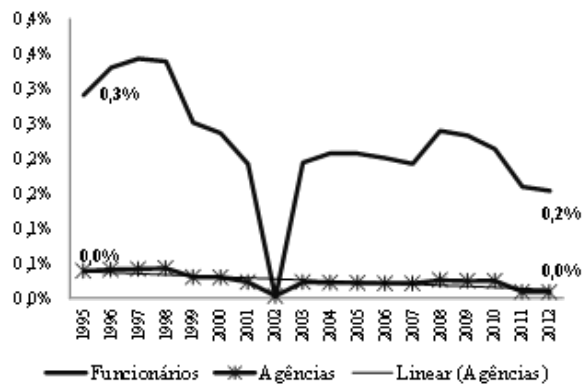

Fonte: Elaboração própria com base nos dados do Banco Central do Brasil.

Recebido em: 03/01/2014. Aceito em: 24/09/2014. 